\title{
Characterization and simulation on antireflective coating of amorphous silicon oxide thin films with gradient refractive index
}

Lu Huang a,*, Qi Jin ${ }^{a}$, Xingling Qu a, Jing Jin ${ }^{a}$, Chaochao Jiang ${ }^{\text {a }}$, Weiguang Yang a , Linjun Wang a, Weimin Shi ${ }^{\text {a }}$

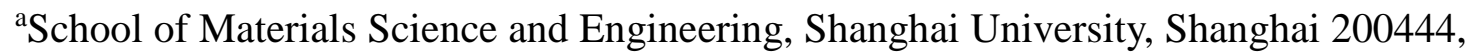
China

*corresponding author: Tel. numbers: +86 21 66138066, E-mail address: lhuang@shu.edu.cn (L. Huang)

\section{ABSTRACT}

The optical reflective properties of silicon oxide $\left(\mathrm{Si}_{\mathrm{x}} \mathrm{O}_{\mathrm{y}}\right)$ thin films with gradient refractive index are studied both theoretically and experimentally. The thin films are widely used in photovoltaic as antireflective coatings (ARCs). An effective finite difference time domain (FDTD) model is built to find the optimized reflection spectra corresponding to structure of $\mathrm{Si}_{\mathrm{x}} \mathrm{O}_{\mathrm{y}} \mathrm{ARCs}$ with gradient refractive index. Based on the simulation analysis, it shows the variation of reflection spectra with gradient refractive index distribution. The gradient refractive index of $\mathrm{Si}_{\mathrm{x}} \mathrm{O}_{\mathrm{y}} \mathrm{ARCs}$ can be obtained in adjustment of $\mathrm{SiH}_{4}$ to $\mathrm{N}_{2} \mathrm{O}$ ratio by plasma-enhanced chemical vapor deposition (PECVD) system. The optimized reflection spectra measured by UV-visible spectroscopy confirms to agree well with that simulated by FDTD method. 
Keywords: antireflective coating; amorphous silicon oxide; gradient refractive index; finite difference time domain

\section{INTRODUCTION}

In the recent years, amorphous silicon $(\alpha-\mathrm{Si})$ thin films on glass substrates have attracted a great deal of attention in photovoltaics, microelectronics and display technologies because of its potential applications for electronic devices, especially thin film solar cells [1-3]. Efficient solar cells must satisfy two kinds of requirements: both strongly optical absorption and effectively electrical transportation. To enhance performance of antireflection and passivation, dielectric oxide layers must be selected to deposit on the surface of $\alpha$-Si thin films. The antireflective coatings (ARCs) have been widely used in manufacturing process of conventional crystalline solar cells (c-Si) to benefit optical absorption, such as silicon nitride $\left(\mathrm{Si}_{\mathrm{x}} \mathrm{N}_{\mathrm{y}}\right)$ deposited on the surface of n-type c-Si [4-6] and aluminum oxide $\left(\mathrm{Al}_{\mathrm{x}} \mathrm{O}_{\mathrm{y}}\right)$ prepared on the surface of p-type c-Si [7-9]. Because of the match of lattice to $\alpha$-Si substrates, amorphous silicon oxide $\left(\mathrm{Si}_{\mathrm{x}} \mathrm{O}_{\mathrm{y}}\right)$ thin films have been used to prepare ARCs by plasma-enhanced chemical vapor deposition (PECVD) [10-11], magnetron sputtering [12-13] and sol-gel methods [14-16]. Compared to physical vapor deposition (PVD) method, it is more suitable to prepare multilayer films with different refractive index by PECVD method. The average reflectance for double-layer ARCs are lower over a broader wavelength range than for a single-layer ARC, because single-layer ARC has only minimal point of reflectance [17-18]. With these requirements, double-layer $\mathrm{Si}_{\mathrm{x}} \mathrm{O}_{\mathrm{y}}$ 
ARCs with gradient refractive index not only decrease electrical recombination effectively, but also enhance optical antireflection strongly [19-20]. However, it is worth discussing how to enhance antireflective effect of $\alpha$-Si thin film solar cells through different distribution structures of $\mathrm{Si}_{\mathrm{x}} \mathrm{O}_{\mathrm{y}}$ ARCs.

In this paper, we present theoretical and experimental study of optical reflective properties of $\mathrm{Si}_{\mathrm{x}} \mathrm{O}_{\mathrm{y}} \mathrm{ARCs}$ with gradient refractive index. The finite difference time domain (FDTD) method is used to study the light-modulated characteristics of ARCs with gradient refractive index. Reflection spectra for different distribution structures of $\mathrm{Si}_{\mathrm{x}} \mathrm{O}_{\mathrm{y}}$ ARCs with gradient refractive index are simulated by FDTD method. This experimental work aims to focus on the correlation between reflection spectra and gradient refractive index distribution. Surface characterization and FDTD simulation analysis of $\mathrm{Si}_{\mathrm{x}} \mathrm{O}_{\mathrm{y}} \mathrm{ARCs}$ with gradient refractive index are investigated simultaneously.

\section{EXPERIMENTAL DETAILS}

The hydrogenated amorphous silicon oxide $\left(\mathrm{Si}_{\mathrm{x}} \mathrm{O}_{\mathrm{y}}: \mathrm{H}\right)$ thin films are prepared by the following procedure. First, $\mathrm{Si}_{\mathrm{x}} \mathrm{O}_{\mathrm{y}}: \mathrm{H}$ films as a layer is deposited on the glass substrates using PECVD by silane $\left(\mathrm{SiH}_{4}\right)$, nitrous oxide $\left(\mathrm{N}_{2} \mathrm{O}\right)$ and hydrogen $\left(\mathrm{H}_{2}\right)$. The experimental parameters of deposited $\mathrm{Si}_{\mathrm{x}} \mathrm{O}_{\mathrm{y}}: \mathrm{H}$ thin films are shown in Tab.1. The PECVD system is HLF-400 made in Beijing Beiyi Innovation Vacuum Technology Co. Ltd. Before the thin films are deposited on glass substrate, heat-resistant tape has been adhered to the corner of glass substrate. After we finish depositing $\mathrm{Si}_{\mathrm{x}} \mathrm{O}_{\mathrm{y}}: \mathrm{H}$ thin films and uncover tape from the substrate, the thickness of thin film is measured on 
the step between glass substrate and thin films by stylus profiler. Thickness measurement of stylus profiler is Vecco Dektak 150. Then double-layer structures are formed on the surface of first layer according to above procedure again. All of samples have been dehydrogenated, after thin films were annealed in vacuum condition at $200^{\circ} \mathrm{C}$ for 30 minutes.

The structural orientation of $\mathrm{Si}_{\mathrm{x}} \mathrm{O}_{\mathrm{y}}$ films are measured by a D/Max-2200 X-ray diffractometer (XRD) of Rigaku using the $\mathrm{Cu} \mathrm{Ka}$ radiation. The cross-section morphology and element composition of thin films is characterized respectively by scanning electron microscope (SEM) and energy dispersive spectrometer (EDS) made by JEOL JSM-6700F. The refractive index and thickness are measured by spectroscopic ellipsometer of Sentech SE-400adv. UV-visible reflection spectra are performed by Hitachi U-2910 spectrophotometer.

\section{RESULTS AND DISCUSSION}

\subsection{Structural modeling}

In this paper, the software of FDTD Solution is used as analysis for simulating different distribution structures of $\mathrm{Si}_{\mathrm{x}} \mathrm{O}_{\mathrm{y}} \mathrm{ARCs}$ with gradient refractive index. The size of rectangular model is that the length, width and height are $2.5 \mu \mathrm{m}, 2.5 \mu \mathrm{m}$ and $0.1 \mu \mathrm{m}$ respectively. The physical and optical values of silicon oxide materials are used as parameters in the simulation. Different structures of $\mathrm{Si}_{\mathrm{x}} \mathrm{O}_{\mathrm{y}} \mathrm{ARCs}$ with gradient refractive index are selected to simulate the properties of optical reflection. The optimal results can be analyzed to obtain the lowest average reflectance in the 
wavelength range of visible light.

The basic cross-section structures of single ARC and double ARCs on the substrate have been shown in Fig. 1(A) and Fig. 1(B) respectively. The reflectance of incident light of wavelength $\lambda$ from the surface of substrate covered by a single non-absorbing layer is given by Eq. 1:

$$
R=\frac{r_{1}^{2}+r_{2}^{2}+2 r_{1} r_{2} \cos 2 \theta}{1+r_{1}^{2} r_{2}^{2}+2 r_{1} r_{2} \cos 2 \theta}
$$

where $r_{1}$ and $r_{2}$ are the individual Fresnel reflectance given by Eq. 2 :

$$
r_{1}=\frac{n_{0}-n_{1}}{n_{0}+n_{1}}, r_{2}=\frac{n_{1}-n_{s}}{n_{1}+n_{s}}
$$

and $\theta$ is the phase difference of the single layer, $\beta$ is refractive angle given by Eq.3:

$$
2 \theta=\frac{4 \pi n_{1} d_{1}}{\lambda \cos \beta}
$$

And $n_{1}$ is the refractive index of the thin film, $d_{1}$ is its thickness, and $n_{s}$ is the refractive index of the substrate. The reflectance exists minimum at a quarter wavelength where $n_{1} d_{1}=\lambda_{0} / 4$ and for odd multiples of $\lambda_{0} / 4$. This minimal value is given by Eq. 4:

$$
R=\left[\left(n_{1}^{2}-n_{0} n_{s}\right) /\left(n_{1}^{2}+n_{0} n_{s}\right)\right]^{2}
$$

And $\mathrm{R}$ equals zero if it meets Eq. 5. Since $\mathrm{n}_{0}$ equals one for air medium, the refractive index of the film should equal the square root of index of the substrate for zero reflectance. The reflective value becomes higher, if it is higher or lower than this quarter wavelength value due to variations in the refractive index with wavelength.

$$
n_{1}=\left(n_{0} \times n_{s}\right)^{1 / 2}
$$

Lower average reflectance can be obtained using double ARCs instead of single 
layer, where the inner layer next to the substrate and the outer layer upon the inner layer. The double layer system is a better match between the high refractive index of the substrate and the low refractive index of air. The reflectance of light from the surface of the structure is given by Eq. 6:

$$
\begin{aligned}
R= & r_{1}^{2}+r_{2}^{2}+r_{3}^{2}+r_{1}^{2} r_{2}^{2} r_{3}^{2}+2 r_{1} r_{2}\left(1+r_{3}^{2}\right) \cos 2 \theta_{1}+2 r_{2} r_{3}\left(1+r_{1}^{2}\right) \cos 2 \theta_{2} \\
& +2 r_{1} r_{3} \cos 2\left(\theta_{1}+\theta_{2}\right)+2 r_{1} r_{2}^{2} r_{3} \cos 2\left(\theta_{1}-\theta_{2}\right) \\
& +2 r_{1}^{2} r_{2}^{2}+r_{1}^{2} r_{3}^{2}+r_{2}^{2} r_{3}^{2}+2 r_{1} r_{2}\left(1+r_{3}^{2}\right) \cos 2 \theta_{1}+2 r_{2} r_{3}\left(1+\theta_{2}^{2}\right)+2 r_{1} r_{2}^{2} r_{3} \cos 2\left(\theta_{1}-\theta_{2}\right)
\end{aligned}
$$

where $r_{1}, r_{2}$ and $r_{3}$ are the individual Fresnel reflectance given by Eq. 7:

$$
r_{1}=\frac{n_{0}-n_{1}}{n_{0}+n_{1}}, r_{2}=\frac{n_{1}-n_{2}}{n_{1}+n_{2}}, r_{3}=\frac{n_{2}-n_{s}}{n_{2}+n_{s}}
$$

where $n_{s}$ is now the index of the substrate, $\theta_{1}, \theta_{2}$ are the phase difference and $\beta, \gamma$ are refractive angle of the double layers given by Eq. 8:

$$
2 \theta_{1}=\frac{4 \pi n_{1} d_{1}}{\lambda \cos \beta}, 2 \theta_{2}=\frac{4 \pi n_{2} d_{2}}{\lambda \cos \gamma}
$$

The reflectance has either a minimum or a local maximum for quarter wavelength optical films $\left(n_{1} d_{1}=n_{2} d_{2}=\lambda_{0} / 4\right)$. This reflectance is given by Eq. 9:

$$
R=\left[\left(n_{1}^{2} n_{s}-n_{0} n_{2}^{2}\right) /\left(n_{1}^{2} n_{s}+n_{0} n_{2}^{2}\right)\right]^{2}
$$

Which $\mathrm{R}$ approaches zero if the condition meets $n_{2}^{2} / n_{1}^{2}=n_{s} / n_{0}$, and approaches a local maximum with zero reflectance on either side if the condition meets $n_{1} n_{2}=n_{0} n_{s}$. Therefore the average reflectance for double ARCs are lower over a broader wavelength range than for a single ARC, because single ARC has only minimal value of reflectance [21].

\subsection{Morphology and structure}

We select ten kinds of samples deposited by different gas ratio of $\mathrm{SiH}_{4}$ to $\mathrm{N}_{2} \mathrm{O}$, 
such as 1:0.5, 1:1, 1:2 and 1:3 respectively, to investigate the cross-section morphology of thin films. The related experimental and measured parameters of samples for single- and double-layer films have been shown in Tab. 2.

The characterization of XRD patterns is also displayed in Fig.2. In the picture, $\mathrm{Si}_{\mathrm{x}} \mathrm{O}_{\mathrm{y}}$ and $\mathrm{Si}$ phase can be obtained through different peak shift. The $\mathrm{Si}_{\mathrm{x}} \mathrm{O}_{\mathrm{y}}$ exhibits a broad peak at $\sim 28^{\circ}$ (sample c in Fig.2). Because $\mathrm{Si}_{\mathrm{x}} \mathrm{O}_{\mathrm{y}}$ thin films still includes parts of amorphous phase, the broad XRD peak at angle $\sim 28^{\circ}$ demonstrates amorphous phase. When the ratio of $\mathrm{SiH}_{4}$ in mixed gas is increased, a new peak of crystalline silicon (c-Si) appears at angle $\sim 30^{\circ}$ corresponding to the standard XRD cards for crystalline Si (111) (sample a and sample b in Fig.2).

The cross-section SEM image of sample $\mathrm{h}$ has been demonstrated in Fig. 3(A), indicating that the $\mathrm{Si}_{\mathrm{x}} \mathrm{O}_{\mathrm{y}}$ film thickness of sample $\mathrm{h}$ is about $112 \mathrm{~nm}$. The double $\mathrm{Si}_{\mathrm{x}} \mathrm{O}_{\mathrm{y}}$ ARCs have been deposited on the glass substrate coating $\mathrm{Sn}_{2} \mathrm{O}_{3}$ :In transparent conductive oxide (ITO), because $\mathrm{Si}_{\mathrm{x}} \mathrm{O}_{\mathrm{y}}$ layer and glass substrate can be separated obviously by ITO layer from SEM image. The atomic ratio of element $\mathrm{Si}$ to O (x/y) is about $56.59 / 43.41=1.3$, which is characterized by EDS analysis in Fig. 3(B). As a result, sample $\mathrm{h}$ is proven to be the best condition of $\mathrm{Si}_{\mathrm{x}} \mathrm{O}_{\mathrm{y}} \mathrm{ARC}$ with gradient refractive index, which can also be confirmed by optical results experimentally and numerically later.

\subsection{Optical properties}

The refractive index and thickness of $\mathrm{Si}_{\mathrm{x}} \mathrm{O}_{\mathrm{y}}$ thin films measured by spectroscopic 
ellipsometer have been listed in Tab. 2. Especially the correlation between refractive index and gas ratio of single $\mathrm{Si}_{\mathrm{x}} \mathrm{O}_{\mathrm{y}}$ thin films has been shown in Fig. 4. When the ratio of $\mathrm{SiH}_{4}$ in mixed gas is increased, the velocity of growth for $\mathrm{Si}_{\mathrm{x}} \mathrm{O}_{\mathrm{y}}$ thin film becomes faster and the value of refractive index for thin film becomes higher, because the increment of $\mathrm{SiH}_{4}$ ratio is benefit to enhance the thickness of $\mathrm{Si}_{\mathrm{x}} \mathrm{O}_{\mathrm{y}}$ thin film in the same deposition time. It is found that the gradient refractive index of $\mathrm{Si}_{\mathrm{x}} \mathrm{O}_{\mathrm{y}} \mathrm{ARC}$ can be obtained by adjustment of $\mathrm{SiH}_{4}$ ratio in mixed gas.

In the structure of ARC on the substrate, the reflection spectra are analyzed by FDTD simulation. The reflection spectra are assumed to vary through different refractive index of single and double layer thin film. The parameters of refractive index and thickness in Tab. 2 are originated from spectroscopic ellipsometer. It is proved theoretically that the correlation between reflection spectra and gradient refractive index distribution can be obtained from FDTD simulation. Meanwhile the reflection spectra of $\mathrm{Si}_{\mathrm{x}} \mathrm{O}_{\mathrm{y}} \mathrm{ARCs}$ with gradient refractive index are deduced from the UV-visible spectrophotometer. We obtained reflection spectra by UV-visible spectral characterization as illustrated in Fig. 5(A) and FDTD simulation as shown in Fig. 5(B). The reflection spectra corresponding to sample $\mathrm{a}, \mathrm{h}, \mathrm{i}$ and $\mathrm{j}$ have been displayed in Fig. 5 respectively.

When the substrate is silicon material, the optimized value of refractive index for single $\mathrm{ARC}$ is about $\sqrt{n_{0} n_{s}}=\sqrt{3.9} \approx 2$ by Eq.5. To obtain lowest average reflectance $(<10 \%)$, the best ratio of gradient refractive index for double ARCs must meet Eq.9. For above reasons, It is found that sample $\mathrm{h}$ is optimized double ARCs 
with gradient refractive index in a broader wavelength range compared to other samples. Therefore the reflection spectra simulated by FDTD method in Fig. 5(B) accords very well to the experimental result characterized by UV-visible spectrophotometer in Fig. 5(A), especially in wavelength range from $500 \mathrm{~nm}$ to 600 nm.

\section{CONCLUSIONS}

In this paper, the single- and double-layer structures of $\mathrm{Si}_{\mathrm{x}} \mathrm{O}_{\mathrm{y}} \mathrm{ARCs}$ with gradient refractive index are numerically and experimentally investigated. The FDTD simulative model is used to predict the optimal reflection spectra corresponding to double ARCs structure of gradient refractive index distribution. The lowest average reflectance $(<10 \%)$ in broader wavelength range is achieved by optimized gas ratio of $\mathrm{SiH}_{4}$ to $\mathrm{N}_{2} \mathrm{O}$ (outer layer 1:3, inner layer 1:1) in the experiment. The optical characterization of thin films with gradient refractive index accords very well to the structural modeling in the simulation.

\section{ACKNOWLEDGMENTS}

The authors gratefully acknowledge the financial support of the project funded by National Science Foundation of China (Grant no. 61404080 and 51202139).

\section{Reference}

[1] A.H. Mahan, Sol. Energy Mater. Sol. Cells, 78 (2003) 299 
[2] G. Fortunato, Thin Solid Films, 296 (1997) 82

[3] S.D. Brotherton, Semicond Sci Technol, 10 (1995) 721

[4] S. Duttagupta, F. J. Ma, B. Hoex, A. G. Aberle, Sol. Energy Mater. Sol. Cells, 120 (2014) 204

[5] N. Balaji, K. Song, J. Choi, C. Park, J. Yi, Curr. Appl. Phys., 13 (2013) 1826

[6] H. P. Zhou, D. Y. Wei, L. X. Xu, Y. N. Guo, S. Q. Xiao, S. Y. Huang, S. Xu, Appl. Surf. Sci., 264 (2013) 21

[7] Q. Qiao, H. Y. Lu, J. Ge, X. Xi, R. L. Chen, J. Yang, J. B. Zhu, Z. R. Shi, J. H. Chu, Appl. Surf. Sci., 305 (2014) 439

[8] H. Lee, T. Tachibana, N. Ikeno, H. Hashiguchi, K. Arafune, H. Yoshida, S. I. Satoh, T. Chikyow, A. Ogura, Appl. Phys. Lett, 100 (2012) 143901

[9] T. Dullweber, C. Kranz, B. Beier, B. Veith, J. Schmidt, B. F. P. Roos, O. Hohn, T. Dippell, R. Brendel, Sol. Energy Mater. Sol. Cells, 112 (2013) 196

[10] L. Remache, E. Fourmond, A. Mahdjoub, J. Dupuis, M. Lemiti, Mat. Sci. Eng. B: Solid, 176 (2011) 45

[11] Z. Z. Chen, P. Sana, J. Salami, A. Rohatgi, IEEE T. Electron Dev., 40 (1993) 1161

[12] B. He, H. Z. Wang, Y. G. Li, Z. Q. Ma, J. Xu, Q. H. Zhang, C. R. Wang, H. Z. Xing, L. Zhao, Y. C. Rui, J. Alloy. Compd., 581 (2013) 28

[13] W. B. Qiu, Y. H. Ma, J. Zhao, J. X. Wang, M. K. Li, S. Y. Li, J. Q. Pan, Japn. J. Appl. Phys., 53 (2014) 021501

[14] N. Iari, S. Ahangarani, A. Shanaghi, J. Mater. Eng. Perform., 24 (2015) 2645

[15] S. Y. Lien, D. S. Wuu, W. C. Yeh, J. C. Liu, Sol. Energy Mater. Sol. Cells, 90 (2006) 2710

[16] H. Y. Li, H. Xiong, Y. X. Tang, L. L. Hu, Rare Metal Mat. Eng., 39 (2010) 145 
[17] J. J. Liu, W. J. Ho, Y. Y. Lee, C. M. Chang, Thin Solid Films, 570 (2014) 585

[18] D. Z. Li, D. Y. Wan, X. L. Zhu, Y. M. Wang, Z. Han, S. S. Han, Y. K. Shan, F. Q. Huang,

Sol. Energy Mater. Sol. Cells, 130 (2014) 505

[19] L. Zhao, Y. H. Zuo, C. L. Zhou, H. L. Li, H. W. Diao, W. J. Wang, Solar Energy, 85 (2011)

530

[20] R. Xu, X. D. Wang, L. Song, W. Liu, A. Ji, F. H. Yang, J. M. Li, Opt. Express, 20 (2012) 5061

[21] H. J. Hovel, Semiconductors and Semimetals, Volume 11, Solar Cells (Academic Press, USA, 1975)

\section{Table Caption:}

Table 1 Experimental parameters of $\mathrm{Si}_{\mathrm{x}} \mathrm{O}_{\mathrm{y}}: \mathrm{H}$ thin film samples deposited by PECVD system

Table 2 The refractive index and thickness of $\mathrm{Si}_{\mathrm{x}} \mathrm{O}_{\mathrm{y}} \mathrm{ARC}$ samples for different gas ratio

\section{Figure Caption:}

Fig. 1 The basic cross-section structures of (A) single ARC on the substrate (B) double ARCs on the substrate

Fig. 2 The characterization of XRD patterns for sample a, b and c 
Fig. 3 (A) The cross-section structure of sample h characterized by SEM (B) The weight and atomic percentage of element for sample $\mathrm{h}$ characterized by EDS

Fig. 4 The correlation between refractive index and gas ratio of $\mathrm{SiH}_{4}$ to $\mathrm{N}_{2} \mathrm{O}$ for single $\mathrm{Si}_{\mathrm{x}} \mathrm{O}_{\mathrm{y}}$ thin films

Fig. 5 (A) UV-visible reflection spectra and (B) FDTD simulative reflection spectra of sample a, h, $\mathrm{i}$ and $\mathrm{j}$ 


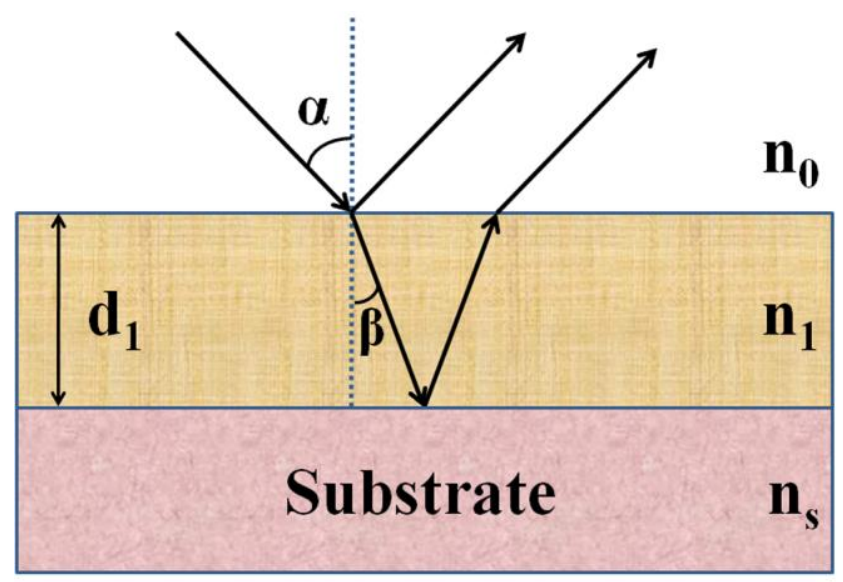

(A)

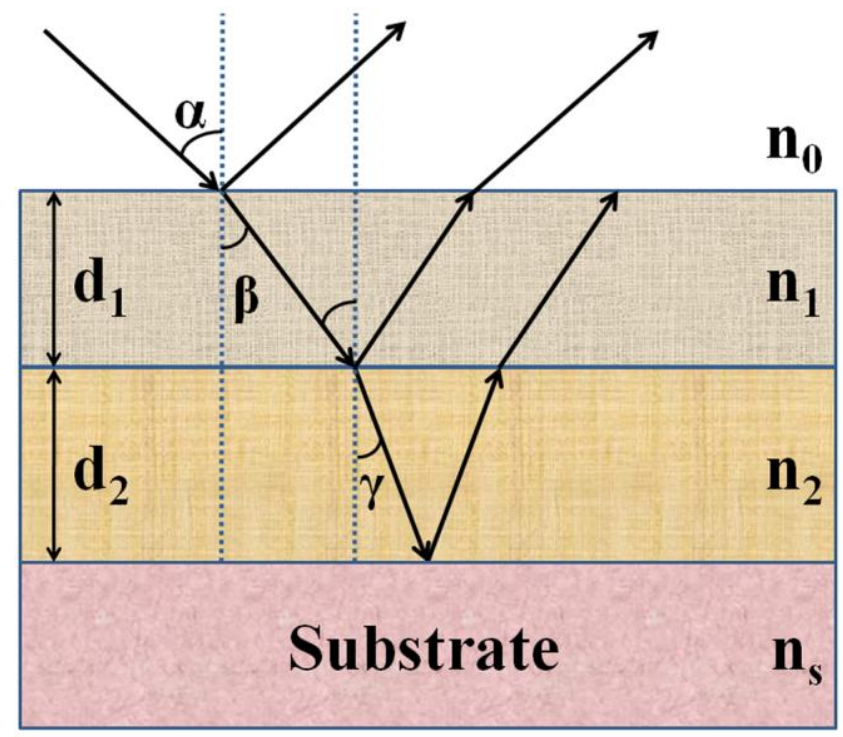

(B) 


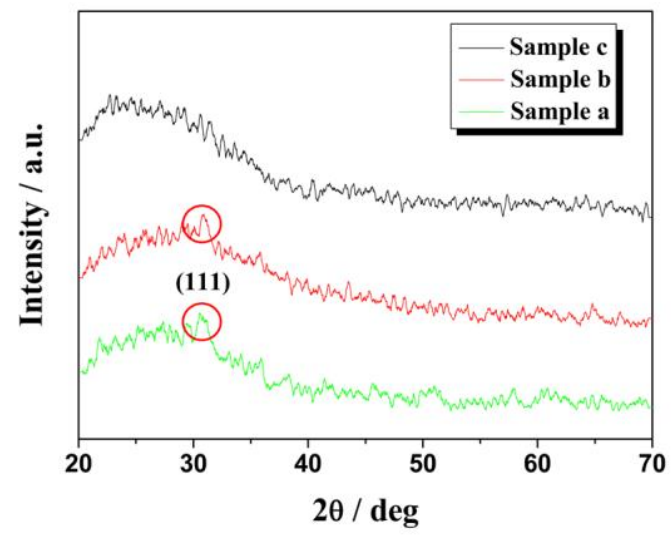




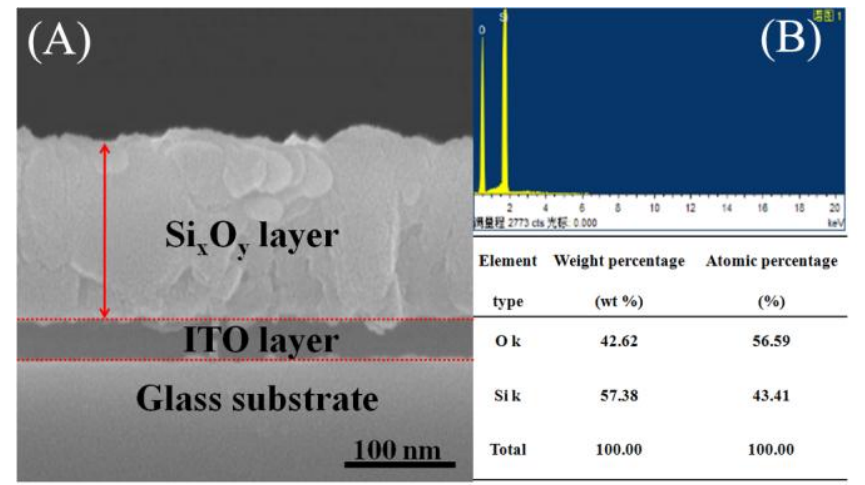




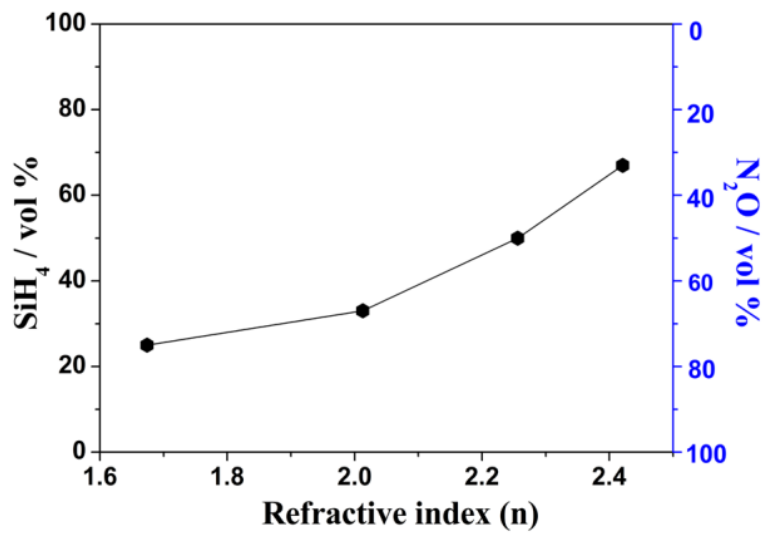



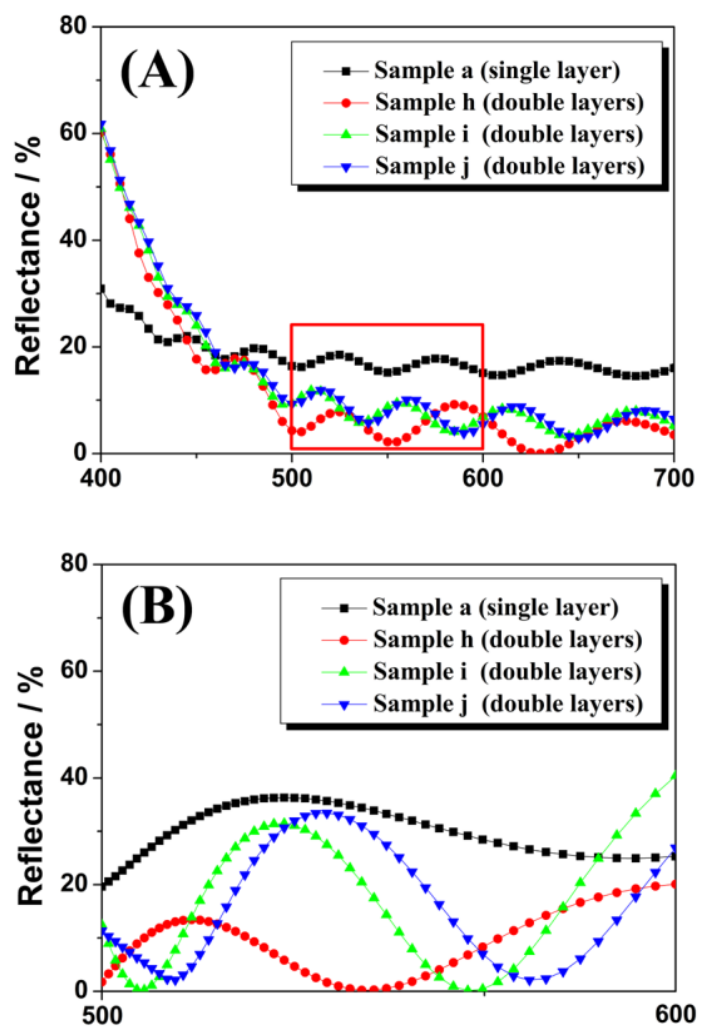

Wavelength / nm 
Table 1

\begin{tabular}{cc}
\hline Parameters of deposited $\mathrm{Si}_{\mathrm{x}} \mathrm{O}_{\mathrm{y}}: \mathrm{H}$ thin film & Specific values \\
\hline Pressure (Torr) & $0.4-0.6$ \\
Temperature $\left({ }^{\circ} \mathrm{C}\right)$ & $200-250$ \\
The $\mathrm{Ar}_{2}$ flow of pretreatment $(\mathrm{sccm})$ & 30 \\
Frequency $(\mathrm{M} \mathrm{Hz})$ & 13.56 \\
RF power $(\mathrm{W})$ & $60-80$ \\
\hline
\end{tabular}


Table 2

\begin{tabular}{|c|c|c|c|}
\hline Sample No. & $\mathrm{SiH}_{4}: \mathrm{N}_{2} \mathrm{O}: \mathrm{H}_{2}(\mathrm{Vol} \%)$ & Refractive index & Thickness (nm) \\
\hline $\mathrm{a}$ & $10: 5: 100(1: 0.5: 10)$ & 2.421 & 95.7 \\
\hline $\mathrm{b}$ & $10: 10: 100(1: 1: 10)$ & 2.256 & 84.8 \\
\hline $\mathrm{c}$ & $10: 20: 100(1: 2: 10)$ & 2.013 & 76.4 \\
\hline $\mathrm{d}$ & $8: 24: 80(1: 3: 10)$ & 1.674 & 67.5 \\
\hline $\mathrm{e}$ & $\begin{array}{l}\text { Outer layer: } 10: 10: 100(1: 1: 10) \\
\text { Inner layer: } 10: 5: 100(1: 0.5: 10)\end{array}$ & 2.287 & 118.6 \\
\hline $\mathrm{f}$ & $\begin{array}{l}\text { Outer layer: } 10: 20: 100(1: 2: 10) \\
\text { Inner layer: } 10: 5: 100(1: 0.5: 10)\end{array}$ & 2.224 & 107.4 \\
\hline $\mathrm{g}$ & $\begin{array}{l}\text { Outer layer: 8:24:80 (1:3:10) } \\
\text { Inner layer: 10:20:100 (1:2:10) }\end{array}$ & 1.897 & 98.5 \\
\hline $\mathrm{h}$ & $\begin{array}{l}\text { Outer layer: 8:24:80 (1:3:10) } \\
\text { Inner layer: 10:10:100 (1:1:10) }\end{array}$ & 2.064 & 112.5 \\
\hline $\mathrm{i}$ & $\begin{array}{l}\text { Outer layer: 8:24:80 (1:3:10) } \\
\text { Inner layer: 10:5:100 (1:0.5:10) }\end{array}$ & 2.105 & 105.2 \\
\hline $\mathrm{j}$ & $\begin{array}{l}\text { Outer layer: } 10: 20: 100(1: 2: 10) \\
\text { Inner layer: } 10: 10: 100(1: 1: 10)\end{array}$ & 2.093 & 115.7 \\
\hline
\end{tabular}

